\title{
Polymorphisms of cytochrome P450 1A1, glutathione s-transferases M1 and T1 genes in Ouangolodougou (Northern Ivory Coast)
}

\author{
Alfredo Santovito ${ }^{1,2}$, Claudio Burgarello ${ }^{2}$, Piero Cervella ${ }^{1}$ and Massimiliano Delpero ${ }^{1}$ \\ ${ }^{1}$ Department of Animal and Human Biology, University of Turin, Torino, Italy. \\ ${ }^{2}$ Biomedical Laboratory of the Catholic Mission "Father P. Pianzola", Oungolodougou, Ivory Coast.
}

\begin{abstract}
In this study, the frequencies of CYP1A1, GSTM1, and GSTT1 gene polymorphisms were determined in 133 healthy individuals from Ouangolodougou, a small rural town situated in the north of the Ivory Coast. As appeared in several published studies, ethnic differences in these frequencies have been found to play an important role in the metabolism of a relevant number of human carcinogens. In the studied sample, the frequencies of Ile/lle (wild type), Ile/Val (heterozygous variant), and $\mathrm{Val} / \mathrm{Val}$ (homozygous variant) CYP1A1 genotypes were 0.271, 0.692, and 0.037, respectively. Frequencies of GSTM1 and GSTT1 null genotypes were 0.361 and 0.331 , respectively. No significant differences were noted between men and women. In contrast to published data for Africans, CYP1A1 *Val Allele frequency $(0.383)$ was significantly high $(p<0.001)$ in this specific population. For the GSTT1 null genotype, no differences were found between the studied and other African populations, the contrary to what occurred for the GSTM1 null genotype in relation to Gambia and Egypt.
\end{abstract}

Key words: CYP1A1, GSTM1, GSTT1, genetic polymorphism, Ouangolodougou.

Received: November 13, 2009; Accepted: January 26, 2010.

Several polymorphic genetic systems have been used to study human genetic variation. Herein we report for a sample from the Ivory Coast on the frequencies of three polymorphic metabolic genes that have been found to play an important role in the metabolism of a relevant number of human carcinogens: the Cytochrome P450 1A1 (CYP1A1), the Glutathione S-transferases (GST) T1 and the GSTM1 genes. Several published studies pointed to ethnic differences in the frequencies of gene polymorphisms, shown to be associated with several types of cancer. The CYP1A1 gene is a component of the phase I cytochrome P450 superfamily, which plays a primary role in the metabolism of polycyclic aromatic hydrocarbons. Its gene product catalyses the first step in the conversion of several environmental carcinogens into their ultimate DNA-binding carcinogenic form (for a review see Indulski and Lutz, 2000). The human CYP1A1 gene is highly polymorphic. In certain populations, such as the Japanese and Chinese, the amino acid substitution CYP1A1 Ile(462)Val has been reported to be associated with a higher risk of certain types of cancer, as lung cancer (Chen et al., 2001), although in other populations, evidence of this association lacks support (McGrath et al., 2007). These contradictory results could be explained by the distinct genetic backgrounds of the investigated populations, as well as other non-genetic factors.

Send correspondence to Alfredo Santovito. Dipartimento di Biologia Animale e dell'Uomo, Via Accademia Albertina n. 13, 10123 Torino, Italy. E-mail: alfredo.santovito@unito.it.
Glutathione S-transferases, found in virtually all eukaryotes, represent one of the major groups of phase II detoxifying enzymes, having evolved to provide organic protection against toxic substances present in food and the environment (Nebert et al., 1996). The mechanism involves the binding of glutathione to insoluble electrophilic substrates, thereby converting them into a soluble form (Perera, 1997). GSTT1 and GSTM1 genes have long been known to be polymorphic in humans by the deletion of a segment of DNA, with the subsequent lack of protein synthesis in homozygous individuals. As a result of deletions at either of the two loci, and the consequent reduced detoxification of xenobiotics, an individual may become susceptible to diseases produced by toxic substances present in the environment (Roy et al., 2001). Deletion polymorphism in GST genes (non-functional alleles) has been found to be associated with the development of certain types of cancer, such as oral cancer (Cha et al., 2007), chronic myeloid leukaemia (Bajpai et al., 2007), bladder cancer (Ouerhani et al., 2006), and colon cancer (Gertig et al., 1998). Although variability in the distribution of GSTM1 and GSTT1 null genotypes has been reported in diverse ethnic groups (Nelson et al., 1995; Garte et al., 2001), sparse data are available for West Africa (Wild et al., 2000). The aim herein was to investigate the genetic variability at CYPIA1 and GSTs loci in an African population from the Ivory Coast, for which no data has been published to date on metabolic gene polymorphisms. 
Sampling was undertaken in Ouangolodougou, a small rural town of 20,000 inhabitants located in the north Ivory Coast, this representing the last frontier zone between the Ivory Coast, Mali and Burkina Faso. One hundred and thirty-three individuals ( 62 males and 71 females, mean age $31.9 \pm 14,5)$ were analyzed. All were healthy volunteers and had received prior information regarding the study.

Peripheral blood samples (5-10 $\mathrm{mL}$ venipuncture) were collected in heparinized vacutainers and stored at $-20{ }^{\circ} \mathrm{C}$. The Chelex ${ }^{\circledR}$ solution protocol was used to extract DNA, as described by Walsh et al. (1991). GSTM, GSTT1 and CYP1A1 genotypes were defined by polymerase chain reaction (PCR), using primers and reaction profiles as described by Zhong et al. (1993), Pemble et al. (1994) and Chen et al. (2001), respectively. PCR reactions were carried out in a total volume of $25 \mu \mathrm{L}$ containing $10 \mathrm{ng}$ of DNA (template), with a final concentration of $1 \mathrm{X}$ Reaction Buffer, $1.5 \mathrm{mM}$ of $\mathrm{MgCl}_{2}, 5 \%$ of DMSO, $250 \mu \mathrm{M}$ of dNTPs, $0.5 \mu \mathrm{M}$ of each primer, and $1 \mathrm{U} /$ sample of Taq DNA polymerase (Fischer, U.S.). PCR products were separated by electrophoresis on a 3\% agarose gel and visualized by ethidium bromide staining. The expected size of amplified CYP1A1 products was 162 base pairs (bp), whereas in the case of GSTM1, GSTT1 and $\beta$-globine (used as internal control), the expected sizes were 230,480 and $110 \mathrm{bp}$, respectively. Homozygous null genotypes of GSTM1 and GSTT1 were determined by identifying the negative band for each size (with the simultaneous presence of the positive control), whereas positive bands meant the sample was homo- or heterozygous for the indicated alleles. A genotype with homozygous deletion of the GST genes is denominated "GST-null", whereas a genotype having at least one copy of the gene is "GST-positive". In order to validate the obtained results, about $20 \%$ of the total sample $(n=30)$ was genotyped independently by a second researcher.
Allele and genotype frequencies of the CYP1A1 gene were calculated using GENEPOP Version 4.0 (Raymond and Rousset, 1995). Hardy-Weinberg equilibrium (HWE) and comparisons among age-groups were evaluated by the Chi-square $\left(\chi^{2}\right)$ test with a $95 \%$ confidence interval. Observed allele frequencies were also compared with those reported for other populations worldwide, through the analysis of contingency tables also by $\chi^{2}$-testing.

The frequencies of CYP1A1 and GSTs allelic polymorphisms in a sample from the north Ivory Coast population, were analyzed. No significant differences were found between men and women in the allele frequency of each gene $(p>0.05)$, thus possibly implying the absence of differences by sex in these detoxifying enzymes.

The observed frequencies of the CYP1A1 Ile/Ile (wild type), Ile/Val (heterozygous variant) and Val/Val (homozygous variant) genotypes were $0.271,0.692$, and 0.037 , respectively (Table 1). Differences in CYP1A1 allele frequency distribution were reported among various ethnic groups (Garte, 1998; Garte et al., 2001). In the studied Ivory Coast population, *Val allele frequency was significantly $(\mathrm{p}<0.001)$ high $(0.383)$, as compared to the few data published for Africans (Table 2). This difference in CYP1A1 polymorphism distribution among Africans could probably be attributed to the different evolutionary histories of the studied ethnic groups, although, as this polymorphism is not neutral, the distinctive selective pressure exerted by chemicals on different populations cannot be excluded. The high heterozygosity frequency value found for CYP1A1 gene (0.692) is congruent with many global surveys of genetic markers, these indicating that diversity in African populations is consistently greater than in other populations (Garrigan and Hammer, 2006). On the other hand, the excess of heterozygotes gave rise to a deviation from HWE $(\mathrm{p}<0.05)$. Moreover, a selective pressure ex-

Table 1 - Genotype and allele Frequencies at CYP1A1 and GSTs loci in the Ouangolodougou population $(\mathrm{n}=133)$

\begin{tabular}{|c|c|c|c|c|}
\hline Genotype & Observed subjects (frequency) & Expected subjects (frequency) & $\chi^{2}(1$ d.f. $)$ & Allele (frequency) \\
\hline \multicolumn{5}{|l|}{$C Y P 1 A 1$} \\
\hline Ile/Ile & $36(0.271)$ & $51(0.383)$ & 4.41 & Ile $(0.617)$ \\
\hline Ile/Val & $92(0.692)$ & $63(0.474)$ & 13.35 & Val $(0.383)$ \\
\hline $\mathrm{Val} / \mathrm{Val}$ & $5(0.037)$ & $19(0.143)$ & 10.32 & \\
\hline Total & & & 28.08 & \\
\hline \multicolumn{5}{|l|}{ GSTM1 } \\
\hline Present & $85(0.639)$ & & & \\
\hline Null & $48(0.361)$ & & & \\
\hline \multicolumn{5}{|l|}{ GSTT1 } \\
\hline Present & $89(0.669)$ & & & \\
\hline GSTM1 null and GSTT1 null & $19(0.143)$ & & & \\
\hline
\end{tabular}

$\mathrm{n}=$ number of tested individuals. 
Table 2 - Frequency of $C Y P 1 A 1$ and GSTs null genotypes in certain African populations.

\begin{tabular}{|c|c|c|c|c|c|}
\hline Population & $\mathrm{n}$ & GSTM1 null frequency & $\mathrm{n}$ & GSTT1 null frequency & Reference \\
\hline Africans & 114 & 0.330 & 114 & 0.250 & Dandara et al. (2002) \\
\hline Africans & 479 & 0.267 & & & Garte et al. (2001) \\
\hline Egypt & 200 & 0.555 & 200 & 0.295 & Hamdy et al. (2003) \\
\hline Gambia & 337 & 0.202 & 326 & 0.371 & Wild et al. (2000) \\
\hline Ivory Coast & 133 & 0.361 & 133 & 0.331 & Present study \\
\hline Tunisia & 79 & 0.456 & 79 & 0.443 & Ouerhani et al. (2006) \\
\hline Population & $\mathrm{n}$ & Ile allele frequency & & & Reference \\
\hline Africans & 114 & 114 & 0.987 & & Dandara et al. (2002) \\
\hline Africans & 445 & 445 & 0.993 & & Garte et al. (2001) \\
\hline African-Americans & 290 & 290 & 0.969 & & Taioli et al. (1998) \\
\hline African-Americans & 539 & 539 & 0.970 & & Garte (1998) \\
\hline African-Brazilians & 231 & 231 & 0.855 & & Gaspar et al. (2002) \\
\hline African-Brazilians & 21 & 21 & 0.905 & & Hamada et al. (1995) \\
\hline Benin & 94 & 94 & 1.000 & & Jiang et al. (2005) \\
\hline Ivory Coast & 133 & 133 & 0.617 & & Present Study \\
\hline Mali & 116 & 116 & 1.000 & & Garte (1998) \\
\hline Zimbabwe & 225 & 225 & 1.000 & & Masimirembwa et al. (1998) \\
\hline
\end{tabular}

$\mathrm{n}=$ number of tested individuals

erted by xenobiotics on this population cannot be excluded. Although this possibility is consistent with several studies showing the association of this polymorphic gene with risk factors for diseases (Chen et al., 2001), convincing evidence to suggest a role of these polymorphisms in modulating susceptibility to cancer diseases, is lacking (McGrath et al., 2007).

Differences in GSTT1 and GSTM1 frequencies in populations worldwide have already been described (Nelson et al., 1995; Garte et al., 2001). These differences show that GST genotype frequencies are distributed populationwise according to the various ethnic and geographical patterns (Garte et al., 2001; Hatagima et al., 2004). In our sample, the frequencies of GSTM1 and GSTT1 null genotypes were 0.361 and 0.331 respectively, whereas the frequency of individuals lacking both genes was 0.143 (Table 1). GST genotypes were coded as positive (wild-type homozygotes and deletion heterozygotes) or null (homozygous deletion), thereby making direct calculation of HWE impossible. Among Africans, no differences were encountered between the population studied and others analyzed for the GSTT1 locus, whereas for GSTM1 significant differences $(\mathrm{p}<0.05)$ were found with respect to Gambia (0.200, Wild et al., 2000) and Egypt (0.555, Hamdy et al., 2003). In Africa, the genetic structure of many otherwise genetically "neutral" systems, such as mitochondrial DNA variation, has already been demonstrated (Salas et al., 2002). Therefore, it is not surprising to discover differences between west and north African populations. The significant difference in frequency of GTSM1-null alleles be- tween the Ivory Coast, Gambian and Egyptian populations could probably be attributed to diversity in populational history. Moreover, data on the prevalence of various diseases, especially those related to local exposure to toxic substances, are unavailable. Therefore, among Africans it is difficult to ascertain the cause of ethnic variation in the frequency of "null" genotypes, and the implications therefrom on the epidemiological profiles of metabolic diseases.

In conclusion, we reported on novel frequency data as regards CYP1A1, GSTM1 and GSTT1 gene polymorphisms in a north Ivory Coast population, thereby extending previous observations obtained from other African populations. Although these gene polymorphisms are not neutral, and thus cannot be used in anthropological studies as genetic markers are subject to stochastic processes, knowledge of their frequency distribution in the Ivory Coast could be helpful in understanding their roles as genetic susceptibility markers in African populations.

\section{Acknowledgments}

We would like to thank the Sisters Bruna, Anna and Teresa, for their technical and logistic support. We also thank the Ouangolodougou community for their warm welcome. This work was supported by grants from the "Ministero dell'Università e della Ricerca Scientifica (MURST)”.

\section{References}

Bajpai P, Tripathi AK and Agrawal D (2007) Increased frequencies of glutathione-S-transferase (GSTM1 and GSTT1) null 
genotypes in Indian patients with chronic myeloid leukaemia. Leuk Res 31:1359-1363.

Cha IH, Park JY, Chung WY, Choi MA, Kim HJ and Park KK (2007) Polymorphisms of CYP1A1 and GSTM genes and susceptibility to oral cancer. Yonsei Med J 48:233-239.

Chen S, Xue K, Xu L, Ma G and Wu J (2001) Polymorphisms of the CYP1A1 and GSTM1 genes in relation to individual susceptibility to lung carcinoma in Chinese population. Mut Res Genom 458:41-47.

Dandara C, Savi J, Masimirembwa CM, Marimba A, Kaaya S, De Sommers K, Snyman JR and Hasler JA (2002) Genetic polymorphism of cytochrome P450 1A1 (Cyp1A1) and glutathione trasferases (M1, T1 and P1) among Africans. Clin Chem Lab Med 40:952-957.

Garrigan D and Hammer MF (2006) Reconstructing human origins in the genomic era. Nat Rev Genet 7:669-680.

Garte S (1998) The role of ethnicity in cancer susceptibility gene polymorphisms: The example of CYP1A1. Carcinogenesis 19:1329-1332.

Garte S, Gaspari L, Alexandrie AK, Ambrosone C, Autrup H, Autrup JL, Baranova H, Bathum L, Benhamou S, Boffetta P et al. (2001) Metabolic gene polymorphism frequencies in control populations. Cancer Epidem Biomar 10:1239-1248.

Gaspar PA, Kvitko K, Papadpolis LG, Hutz MH and Weimer TA (2002) High frequency of CYP1A $1 * 2 \mathrm{C}$ allele in Brazilian populations. Hum Biol 74:235-242.

Gertig DM, Stampfer M, Haiman C, Hennekens CH, Kelsey K and Hunter (1998) Glutathione S-transferase GSTM1 and GSTT1 polymorphisms and colorectal cancer risk: A prospective study. Cancer Epid Biom Prev 7:1001-1005.

Hamada GS, Sugimura H, Suzuki I, Nagura K, Kiyokawa E, Iwase T, Tanaka M, Takahashi T, Watanabe S, Kino I et al. (1995) The heme-binding region polymorphism of cytochrome P450IA1 (CYP1A1), rathern than the RsaI polymorphism of IIE1 (CYPIIE1), is associated with lung cancer in Rio de Janeiro. Cancer Epidem Biomar 4:63-67.

Hamdy SI, Hiratsuka M, Narahara K, Endo N, El-Enany M, Moursi N, Ahmed MS and Mizugaki M (2003) Genotype and allele frequencies of TPMT, NAT2, GST, SULT1A1 and MDR-1 in the Egyptian population. Br J Clin Pharmacol 55:560-569.

Hatagima A, Marques CFS, Krieger E and Feitosa MF (2004) Glutathione S-transferase M1 (GSTM1) and T1 (GSTT1) polymorphisms in a Brazilian mixed population. Hum Biol 76:937-942.

Indulski JA and Lutz W (2000) Metabolic genotype in relation to individual susceptibility to environmental carcinogenesis. Int Arch Occup Environ Health 73:71-85.

Jiang Z, Dalton TP, Jin L, Wang B, Tsuneoka Y, Shertzer HG, Deka R and Nebert DW (2005) Toward the evaluation of function in genetic variability: characterising human SNP frequencies and establishing BAC-transgenic mice carrying the human CYP1A1_CYP1A2 locus. Hum Mutat 25:196206.

Masimirembwa CM, Dandara C, Sommers DK, Snyman JR and Hasler JA (1998) Genetic polymorphism of cytochrome
P4501A1, microsomal epoxide hydrolase, and glutathione S-transferase M1 and T1 in Zimbabweans and Venda of Southern Africa. Pharmacogenetics 8:83-85.

McGrath M, Hankinson SE and De Vivo I (2007) Cytochrome P450 1A1, cigarette smoking, and risk of endometrial cancer (United States). Cancer Causes Control 18:1123-1130.

Nebert DW, McKinnon RA and Puga A (1996) Human drugmetabolizing enzyme polymorphisms: Effects on risk and toxicity of cancer. DNA Cell Biol 15:273-280.

Nelson HH, Wiencke JK, Christiani DC, Cheng TJ, Zuo ZF, Schwartz BS, Lee BK, Spitz MR, Wang M, Xu X et al. (1995) Ethnic differences in the prevalence of the homozygous deleted genotype of glutathione S-transferase theta. Carcinogenesis 16:1243-1245.

Ouerhani S, Tebourski F, Slama MR, Marrakchi R, Rabeh M, Hassine LB, Ayed M and Elgaaïed AB (2006) The role of glutathione transferases M1 and T1 in individual susceptibility to bladder cancer in a Tunisian population. Ann Hum Biol 33:529-535.

Pemble S, Schroeder KR and Spenser SR (1994) Human glutathione-S-transferase theta (GSTT1): cDNA cloning and the characterization of a genetic polymorphism. Biochem $\mathrm{J}$ 300:271-276.

Perera FP (1997) Environment and cancer: Who are susceptible? Science 278:1068-1073.

Raymond M and Rousset F (1995) GENEPOP v. 1.2: Population genetics software for exact tests and ecumenicism. J Hered 86:248-249.

Roy B, Majumder PP, Dey B, Chakraborty M, Banerjee S, Roy M, Mukherjee N and Sil SK (2001) Ethnic differences in distributions of GSTM1 and GSTT1 homozygous "null" genotypes in India. Hum Biol 73:443-450.

Salas A, Richards M, De la Fe T, Lareu MV, Sobrino B, Sánchez-Diz P, Macaulay V and Carracedo A (2002) The making of the African mtDNA landscape. Am J Hum Genet 71:1082-1111.

Taioli E, Ford J, Trachman J, Li Y, Demopoulos R and Garte S (1998) Lung cancer risk and CYP1A1 genotype in African Americans. Carcinogenesis 19:813-817.

Walsh PS, Metzger DA and Higuchi R (1991) Chelex 100 as a Medium for simple extraction of DNA for PCR-based typing from forensic material. BioTechniques 10:506-513.

Wild CP, Yin F, Turner PC, Chemin I, Chapot B, Mendy M, Whittle H, Kirk GD and Hall AJ (2000) Environmental and genetic determinants of aflatoxin-albumin adducts in the Gambia. Int J Cancer 86:1-7.

Zhong S, Wyllie AH, Barnes D, Wolf CR and Spurr NK (1993). Relationship between the GSTM1 genetic polymorphism and susceptibility to bladder, breast and colon cancer. Carcinogenesis 14:1821-1824.

Associate Editor: Francisco Mauro Salzano

License information: This is an open-access article distributed under the terms of the Creative Commons Attribution License, which permits unrestricted use, distribution, and reproduction in any medium, provided the original work is properly cited. 